\title{
CS in Schools: Developing a Sustainable Coding Programme in Australian Schools
}

\author{
Hugh E. Williams* \\ CS in Schools, RMIT University \\ Melbourne, Australia \\ hugh@csinschools.com
}

\author{
Selina Williams \\ CS in Schools, RMIT University \\ Melbourne, Australia \\ selina@csinschools.com
}

\author{
Kristy Kendall ${ }^{\dagger}$ \\ kristy@csinschools.com \\ Toorak College \\ Mount Eliza, Victoria, Australia
}

\begin{abstract}
Digital technology is compulsory in schools in most states at most year levels in Australia. However, a recent survey of over 400 Australian schools in 2019 found that $96 \%$ have had difficulty hiring qualified technology teachers and $39 \%$ of schools have reduced the amount of technology education they offer. We have observed that there is a shortage of teachers who feel qualified to teach coding.

To address this problem, we launched CS in Schools ${ }^{1}$, a successful in-class professional development programme for teachers that helps schools build a robust digital technology capability in their students. Our programme matches pedagogy with content expertise, by matching a volunteer computing professional with a secondary school teacher, and helping that teacher develop their coding skills in the classroom over a six month period. This experience paper describes the approach we took in piloting our programme with 10 teachers in 8 schools who taught over 1,100 students in 2019. We also describe our current scale-up in 2020 to work with around 60 teachers, around 40 volunteers, over 25 schools, and more than 6,000 students. Our goal is to work with hundreds of schools in 2021.
\end{abstract}

\section{CCS CONCEPTS}

- Social and professional topics $\rightarrow$ K-12 education. KEYWORDS

Broadening participation; K-12 education; Teacher professional development

\section{ACM Reference Format:}

Hugh E. Williams, Selina Williams, and Kristy Kendall. 2020. CS in Schools: Developing a Sustainable Coding Programme in Australian Schools. In 2020 ACM Conference on Innovation and Technology in Computer Science Education (ITiCSE'20), June 15-19, 2020, Trondheim, Norway. ACM, New York, NY, USA, 7 pages. https://doi.org/10.1145/3341525.3387422

\footnotetext{
*Also with Melbourne Business School, The University of Melbourne.

$\dagger$ Also with CS in Schools, RMIT University.

${ }^{1}$ https://csinschools.com
}

Permission to make digital or hard copies of part or all of this work for personal or classroom use is granted without fee provided that copies are not made or distributed for profit or commercial advantage and that copies bear this notice and the full citation on the first page. Copyrights for third-party components of this work must be honored

For all other uses, contact the owner/author(s).

ITiCSE '20, June 15-19, 2020, Trondheim, Norway

(C) 2020 Copyright held by the owner/author(s).

ACM ISBN 978-1-4503-6874-2/20/06.

https://doi.org/10.1145/3341525.3387422

\section{INTRODUCTION}

There will be over 100,000 new IT jobs in Australia by 2024 and the "highest policy priority for the digital economy is skills development" [4]. Despite the demand, and IT being one of the highestpaid careers, just under 6,000 students graduated from Australian domestic IT courses in 2017. We believe a significant contributing factor to the lack of demand is the broad absence of a high-quality digital technology programme in schools.

Digital technology is compulsory in public and Catholic schools in most states from $\mathrm{K}-10$ in Australia. This reflects the state and federal governments' understanding of the importance of exposing K-12 students to the fundamentals of computational thinking, information technology, and coding. However, our empirical observation suggests that less than $5 \%$ of schools are teaching the complete required curriculum.

A survey of more than 400 Australian schools [2] found that $96 \%$ have had difficulty hiring qualified technology teachers and $39 \%$ have reduced the amount of technology education they offer. Around $30 \%$ of IT teachers are teaching out of their field of expertise [14]. In particular, we have observed that there is a particular shortage of teachers who are qualified to teach coding. Of course, this is not unique to Australia: most countries have challenges staffing their digital technology classes with appropriatelyqualified teachers, and most countries have unprecendented demand for IT professionals.

We believe that these problems can be addressed through intensive in-class professional development of classroom teachers. Our programme helps teachers learn how to code and teach coding to secondary students. We believe that by giving every student the opportunity to code, we will increase the pipeline of students who study and work in IT; of course, a future longitudinal study is the only way to show this is true. We also believe that our approach is broadly applicable to most countries with similar challenges.

We launched a pilot programme in 2019, with the goal of developing approaches that will scale nationally. It is designed around the fundamental idea of bringing together a content expert from industry with a pedagogy expert in a school to help the pedagogy expert develop the content skills. We believe that if a significant number of teachers can become coding experts then a sustainable and substantial change in the education landscape is possible.

This paper is structured as follows. Section 2 discusses related programmes and approaches to teacher professional development, Section 3 describes our approach at CS in Schools. Section 4 shares the outcomes of work and Section 5 outlines how we have changed and expanded the programme in 2020 based on our learnings from 2019. 


\section{BACKGROUND}

Australia has a shortage of teachers that are qualified to teach digital technology. Unfortunately, an ageing population of predominantly male IT teachers, a decreasing percentage of male teachers overall, and unqualified teachers teaching in the digital technology space does not bode well for addressing the IT skills gap in Australia $[2,14]$.

\subsection{Pre-Service Programmes}

It is possible to increase the pool of qualified IT teachers by adding computer science into the curriculum for pre-service teachers [6, 12] and increasing the population of undergraduate computer science graduates who go on to obtain teaching qualifications [14] However, it is generally agreed that the latter is unlikely to be a rich source of new teachers given the lucrative IT careers that exist outside of teaching. Indeed, in our work over the past two years, we have encountered less than five CS undergraduate qualified teachers in our state.

In the medium term, we believe it is possible to add core computing courses to teaching programmes. However, we do not believe this is achievable in the short term in Australia, nor do we believe that this can transform the landscape of digital technology education in schools on a national scale.

\subsection{Professional Development}

Professional development (PD) of teachers has been widely discussed $[3,8,10]$. Desimone et al. [3] describe six factors of a PD experience:

(1) Reform type-whether the activity is organised as a group activity such as a mentoring relationship, as opposed to a traditional workshop or conference

(2) Duration-how many hours the activity takes and its total duration

(3) Collective participation-the number of teachers from the same school

(4) Active learning-the degree to which there is practical application of the learning, such as marking student work or receiving mentoring feedback

(5) Coherence-how the PD aligns with the teacher's goals and their school, state, and national requirements

(6) Content focus-the degree of focus on deepening knowledge

They have shown that group activities are more effective than traditional workshops or conferences, that having more teachers from the same school participating is more effective than fewer, that active learning is important, and that building on teachers' existing knowledge makes PD more effective. In their study, duration surprisingly had no effect on the effectiveness of PD.

\subsection{Related Work}

There are many out of class programmes, such as the PD associated with The Beauty and foy of Computing [5], online programmes that are offered in Australia through organisations such as CodeClub ${ }^{2}$

\footnotetext{
${ }^{2}$ https://codeclubau.org
}

and the Australian Computing Academy (ACA) ${ }^{3}$, and workshops such as those offered by the ACA and regional offerings such as those through the DLTV ${ }^{4}$. As discussed in Section 2.2, the reform type and the degree of active learning have been shown to affect the success of a PD activity and, as such, there is evidence that inclass PD may be more effective. In any case, our focus in this paper is only on in-class PD programmes.

The type of material that is taught to students is known to have an effect on educational outcomes [9, 13]. For example, students are more engaged when the topic is game design. We are not aware of a study that shows the effect of the type of materials on teacher PD success.

The TEALS programme is similar to our approach $[7,11]$. TEALS builds teacher capacity in CS by pairing four volunteer computing professionals with one teacher, where that teacher has no CS background. TEALS provides workshop-trained volunteers, thirdparty teaching materials, and establishes typically a two-year partnership between the volunteers and the teacher. A volunteer typically visits the classroom two or three times per week. The overall teacher commitment is around 300 hours of in-class PD with their teaching team. The TEALS programme is aimed at teachers who are upskilling to teach AP classes, that is, advanced high school classes that bear university credit.

In a survey of students in the TEALS programme, $45 \%$ said they were more likely to consider a CS career. Around $90 \%$ of teachers said they would be ready to teach CS independently within two years. There is not yet a longitudinal study on the effect of TEALS in increasing participation in IT jobs, nor a study on whether students ultimately study IT or related fields. However, it is clear that TEALS is an effective PD programme.

TEALS is focused on helping upskill teachers to improve outcomes for advanced students in the final years of high school. In contrast, our programme is focused on increasing the pipeline of students who might consider those advanced programmes. Our programme is shorter in duration, aimed at younger students, and covers introductory concepts only; our programme design is aimed at scaling across thousands of schools in just a few years.

\section{THE CS IN SCHOOLS PROGRAMME}

Our goal in creating the CS in Schools programme is to transform CS education in Australia. We want every secondary school student in Australia to have the opportunity to learn how to code as part of their regular classroom education. To achieve this goal, we built a ten-week programme to develop introductory programming skills, and scaffolded this programme so that it is nationally scalable to all secondary school teachers and their students with a high chance of adoption and success.

We launched a pilot of the CS in Schools programme in 2019 after developing the programme throughout 2018. This section shares the details.

\footnotetext{
${ }^{3}$ https://aca.edu.au

${ }^{4}$ https://dltv.vic.edu.au/
} 


\subsection{Approach}

CS in Schools is a volunteer-based programme, and it is free to schools and teachers ${ }^{5}$. We usually pair one volunteer computing professional with a school teacher to help that teacher teach coding and computational thinking in their classroom. We refer to this as a teaching team.

We ask each teaching team to teach the course twice with two different cohorts of students over two consecutive teaching terms or semesters. In the first term, we suggest that the volunteer spends most of the time out the front of the class role modelling how to explain coding, while the teacher learns by observation and manages the classroom. In the second term, we ask that the teacher takes the role at the front of the classroom, and the volunteer provides debugging help to students and mentoring feedback to the teacher. Through teaching our materials twice as a teaching team, we build capability within teachers to ensure they feel confident and competent at teaching students to code using our lesson materials.

We provide the following resources:

- Scaffolded lesson materials including lesson plans, slides, video tutorials, coding activities, extension activities, assignments, and quizzes

- An expert volunteer computing professional

- A two-day training workshop for volunteers, and mid-term evening optional mini-workshops

- Online and phone support

Our course is designed to be taught over 10 weeks at 2 hours of contact time per week for 20 hours in total. The course is aimed at Year 7 teachers and their students, who are typically 13 years of age. Year 7 is the first year of secondary school, that is, the first postprimary school year. Volunteers attend all classes, typically for 2 consecutive hours per week for around 20 weeks in total over a 6 month period; as discussed earlier, volunteers are present for two repetitions of the course.

3.1.1 Teachers and Schools. Eight diverse schools from the state of Victoria participated in the pilot. Six schools were located in or near the capital city of Melbourne, and the other two schools were over 200 kilometres (120 miles) from the city in the regional town of Sale, which has a population of around 15,000. Three schools were independent, private schools with fees ranging from approximately AUD $\$ 10,000$ to AUD\$30,000 per year. Four schools were public schools, including three that are designated as low socioeconomic status (SES); this is similar to Title I in the US. One school was from the Catholic education system.

The smallest school had just over 400 secondary students and largest had almost 1,500. The mean average was 770 students. Most classes had around 25 students, and most schools had between 4 and 8 cohorts of student classes over the year. We provided a volunteer for each class in terms 1 and 2, that is, the first half of the year. At one school, we provided four different volunteers to support one teacher because she taught 2 classes in terms 1 and 2 with a complex weekly timetable.

\footnotetext{
${ }^{5}$ CS in Schools is funded by philanthropic donation.
}

There were ten teachers in the pilot programme. Six of the eight schools had one teacher in the programme, and the remaining two schools had two teachers each.

Eight of the ten teachers in the programme participated in a survey commissioned by the CS in Schools organisation ${ }^{6}$. One teacher had a formal diploma qualification in IT, while the remaining seven did not. All teachers had taught coding-mostly using block-based programming tools-and six of the eight were coordinating the IT programmes in their schools. Six of the eight teachers expressed some confidence in their ability to teach coding before joining the programme. The teacher who expressed the highest confidence shared that "if you asked me to write a program I would probably still get it all wrong but in terms of all the concepts I would get that". Another with some confidence had never taught an IT class.

Our empirical observation of the teachers in the early stages of the programme did not support their self-confidence; we expect that there may have been a significant difference between what we understand as coding as software professionals and what the teachers believed coding was coming into the programme. Indeed, several teachers answered that they had "programmed in HTML" previously, which is a markup language and not a programming language. In the future, we plan to measure coding ability more explicitly and quantitatively using, for example, online coding exercises.

3.1.2 Course Materials. The course is called "Introduction to Coding". The programme covers basic coding topics using Python as the teaching language. The topics covered are coding oriented topics mandated by the Australian Digital Technologies curriculum (ADTC) at the Years 7 and 8 level $^{7}$. We use Python both because of its popularity in industry and also because the ADTC requires the use of a general-purpose programming language. The course concludes with a capstone assignment and roughly two-thirds of the student class time is spent writing code and practicing skills.

We designed and built the course materials ${ }^{8}$. The latest version of our lesson materials contains six core lessons and we recommend that classes spend at least two additional lessons working on the capstone assignment. The remaining two lessons are typically filled using lessons from our library of supplementary lessons; in practice, most schools do not actually have ten weeks in a term because of holidays, school events, or other activities. The eight structured lessons are shown in Table 1.

Each of the lessons in the core syllabus is built around the " $5 \mathrm{Es}$ of Learning” pedagogical model: Engage, Explore, Explain, Elaborate, Evaluate [1]. Each lesson begins with the demonstration of a key concept by exploring and modifying pre-written code. After this, key concepts are explained through slides and activities that increase in difficulty. The final exercise is intentionally designed to be open-ended, and it is accompanied by a video walkthrough. At the end of the lesson, students are asked to reflect on their learnings.

\footnotetext{
${ }^{6}$ The surveying was carried out by staff from the School of Education at RMIT University

${ }^{7}$ https://www. australiancurriculum.edu.au/

${ }^{8}$ See: https://year7.io
} 
Table 1: Core and working lessons in our "Introduction to Coding" course in the CS in Schools programme. The materials are available at https://year 7 . io

\begin{tabular}{lll}
\hline Lesson & Lesson Title & Lesson Topics \\
\hline 1 & Introduction to CS in Schools & Introductions; signups; Hello, world!; Modifying existing code \\
2 & Displaying Text on the Screen and Input & Whitespace; Errors; Program flow; print; input \\
3 & Colour your world! & Displaying text in colours and styles; concatenating strings \\
4 & Variables & String variables; accepting input and storing it; printing variable contents \\
5 & Decisions & Flowcharts; if; equality with ==; indentation \\
6 & Loops & Loops in flowcharts; loops in code; inequality with ! $=$ \\
\hline 7 & Assignment & Introducing the rubric, examples, video guide, and answer template \\
8 & Conclusion & Working lesson; next steps; farewells \\
\hline
\end{tabular}

3.1.3 Volunteers. Volunteers were recruited from local Australian technology companies. We trained fifteen volunteers and twelve participated in the programme.

Eight of the volunteers participated in a survey that we commissioned. Four of the volunteers surveyed had less than 5 years of professional experience, while the other four had 8, 10, 20, and 25 years of experience. Seven volunteers had no first hand experience in the classroom, while the remaining volunteer was studying to become a teacher. Six of the volunteers were software engineers. All volunteers surveyed had a formal computing qualification.

A strong sense of giving back was the key reason for participation. All volunteers wanted to be part of a programme that positioned IT more positively in the education system. Volunteering was also a positive part of the culture of the two organisations that contributed the most volunteers. Another factor that contributed to volunteering was the belief of the importance of the IT sector and its contribution to future economic and social prosperity. The last significant factor was a perception that the education system is not adequately keeping pace with the real world.

3.1.4 Workshop. The volunteers were required to attend a twoday pre-service workshop. We modelled our workshop on TEALS' approach, after consultation with the TEALS team. We spent more time than TEALS focused on equipping volunteers with a basic understanding of what it is like to be in a classroom, basic practices to work with young students, and tips on how to explain coding concepts. The workshop was largely facilitated by teachers and school executives.

We also did something quite different to other workshops by focusing on equipping volunteers with basic presentation skills to effectively explain concepts in the classroom. We asked our volunteers to present a short lesson extracted from our course materials to a small audience of teachers and students. Each volunteer received both verbal and written feedback, and additional mentoring from the CS in Schools staff if required.

3.1.5 Support. We provided volunteers and teachers with their own CS in Schools email address and access to the CS in Schools Slack online community. We created Slack channels for teachers, volunteers, schools, tools, and curriculum discussions. In a typical week, the population of 22 teachers and volunteers, along with the CS in Schools team, posted around 150 messages of which $40 \%$ were in public channels accessible by everyone, $20 \%$ were in private channels that did not include everyone, and $40 \%$ were direct messages between people.

We ran two optional, short mid-programme evening workshops for volunteers. The first was a discussion with the author of the course materials on the course content and tips for explaining coding concepts. The second was run by an experienced teacher and aimed at deepening skills to be an effective partner to a teacher in a Year 7 classroom.

\subsection{Choices}

We observed that many primary schools in Australia have effective coding programmes, usually created through a partnership between an IT specialist and the grade teacher. When students enter secondary school at Year 7, they typically move between classrooms to take different specialised courses such as English, science, music, and mathematics. The teachers are deep content experts, and typically focus on their content area. If there is no dedicated digital technology course, it becomes almost impossible to teach students to code.

Many Australian secondary schools have Year 9 electives in digital technology. In schools with hundreds of students in a year level, a typical enrolment in these technology electives is less than ten students. This is not surprising given that students have had little exposure to coding, and may have preconceptions about whether it is interesting, relevant, or suitable for them. The follow-on effect is low enrolments in final-year Year 12 IT courses; for example, in our state, less than 1,500 students took the most popular IT course in 2018 (less than 200 non-males), while almost 11,000 studied chemistry. A programme similar to TEALS would improve the outcomes for this small cohort of advanced students, but it would not in itself significantly increase the pipeline of students who study Year 12 IT courses.

We decided to begin by launching a Year 7 programme. We typically work with schools that make our coding programme compulsory for all of their Year 7 students, and our programme is aimed at the median student while offering support for weaker students and challenge for advanced students. We found in consultation with schools that it was only practical to launch a course that had the same timetabling quantum as courses such as music, a language, art, or woodwork. We therefore built our course to run for 10 weeks at around 2 contact hours per week. 
We built our own materials because we did not find a complete, scaffolded Year 7 programme that met the Australia curriculum requirements. We believe that our materials increase the chances of teacher success, provide consistent quality in the student experience, and remove barriers to entry with schools.

\section{INITIAL EVALUATION}

We believe our 2019 pilot programme was successful. We completed the pilot with eight diverse schools, ten teachers with different backgrounds, twelve volunteers, and over 1,100 students. Of the 1,100 students, around 600 were non-male. In this section, we share qualitative feedback from teachers and volunteers, and indicative numbers from the programme. We may report student outcomes in the future, but did not seek ethics or other approvals needed to do this.

Seven of the eight schools returned to the programme for 2020 . All of the schools have put new teachers in the programme and the majority have added more than one teacher; the 2020 programme averages over 2 teachers per school, while 2019 averaged just over 1. The school and teacher that have not returned to the programme are continuing to teach our materials to their Year 7 classes.

Nine teachers in the programme confidently taught our Year 7 course in the second half of 2019 without volunteer support; the other teacher did not teach at all. Eight of the ten teachers have returned to participate in a new Year 8 "Intermediate Coding" PD programme that follows the same model.

\subsection{Teacher Experience}

Eight of the ten teachers participated in a survey that we commissioned. All teachers reported increases in their confidence and competence to teach coding because of the CS in Schools pilot. The following comments are typical examples of feedback on participation in the programme:

- "The resources are great. Please keep doing it. Please keep sending volunteers."

- "Amazing to have volunteers [in the classroom] and be able to ask them questions to clarify. Grateful our school chose to put up their hand to do the project, I would love to continue with it."

- "I think it was really beneficial for us to be a part of the pilot. I would like to see it happen again maybe next year."

- "I'd like to deepen the relationship and the partnership."

4.1.1 Teacher Example One. Peter ${ }^{9}$ has 8 years of teaching experience, and has previously taught visuals arts and media. Peter states that "without the CS in Schools programme I would have been able to teach Python but not as well as this. The programme has helped immensely and now I will be able to teach in a really well structured way". He also said that "it was really beneficial for us [the school] to be a part of the pilot".

He also noted that "[The resources] were very well balanced. There were points where I would look at the slides and think: your lessons you've planned have a slide for every single thing that you need to teach."

\footnotetext{
${ }^{9}$ Not his real name. All real names have been changed
}

4.1.2 Teacher Example Two. Isabel has over 25 years of teaching experience, a graduate diploma in IT, and has primarily taught languages. Her confidence before the programme was low and she shared that "I'm not confident to teach a whole [coding] class and I have no platform [tools or environments] to teach coding". After the programme she stated that "My skills are much better. Much better" and that the "the [resources] are very descriptive, with step by step [scaffolding]. You can't go wrong”. She believes strongly in the two-pass model, where a volunteer helps a teacher for two iterations of teaching the materials.

She appreciated the in-class content expertise from the volunteer and shared that "it was amazing just to be taught and I could ask things ... if this happens or I want this how do I do this? This is the bit that I don't like about [studying online] because if you're stuck, you're stuck. If you [are a] beginner and you get stuck, who do you ask if you don't have anybody that can help you?"

4.1.3 Teacher Example Three. Simon is a physical education and biology teacher by training with around 10 years of experience. He is passionate about IT and has been teaching classes for a few years. He shared before the programme: "I have low coding skills. In my IT classes I might have a few kids who code as a hobby who help me".

He appreciated the course materials, sharing that "one of the main benefits of CS in Schools was the activities were there, the curriculum was followed, and it was done. All you really had to do was learn it and implement it". He also appreciated the volunteer supporting his PD, stating that "it's a lot quicker when you've got someone that can ... just help you out in real-time rather than spending an hour or two trying to work something simple out".

\subsection{Volunteer Experience}

Ten of the twelve volunteers completed two school terms of six months and two iterations of the teaching materials with their partner teacher. One volunteer committed initially for only one term, and was replaced by a CS in Schools staff member for the second term. One volunteer withdrew from volunteering after one term and was replaced by a volunteer who took on an additional teacher and school.

Five of the ten volunteers who completed two terms in 2019 are volunteering again in 2020 . One volunteer became a qualified teacher and joined the staff of the school where he was a volunteer, and now teaches CS at that school. Another volunteer joined the CS in Schools organisation. One volunteer remains associated with the programme in an ad hoc mentoring capacity, and two cited changing work circumstances as the reason for not continuing.

Eight of the twelve volunteers participated in a survey commissioned by the CS in Schools organisation.

4.2.1 Workshop. Volunteers had a strong positive impression of the pre-service workshop. Josh ${ }^{10}$ shared that "[Given] only two days and given the constraints they covered a good amount". Brendan said that "It was really interactive which you can't help but find engaging". Teachers as presenters was popular, with Nina saying "Teachers and [the other] speakers were people who had real knowledge of the classroom" and Brendan contributing that "They

\footnotetext{
${ }^{10}$ Not the real names again
} 
knew what they were talking about and did a good job. They were really, really good".

The content was well received, with volunteers happy with the focus on volunteering in a classroom environment. Brendan shared that "There's heaps of stuff they mentioned that we tried, like how to engage students when asking them a question, how to talk to kids when they answer something incorrectly". Kieran was equally positive, sharing that "Once I was in the classroom a lot more of the lessons [from the workshop] became applicable when in front of the class".

Volunteers liked receiving feedback on mock presentations. As Nina said, "[this was] helpful beyond the classroom". Jason stated that it was "not something you learn anywhere else I don't think. I found it super useful, even for work".

\subsection{Areas for Improvement}

Our surveys of teachers and volunteers uncovered several areas for possible improvement:

(1) Authenticity-add more real-world examples to the teaching materials

(2) Flexibility-build a more flexible model, given that every school has a different timetable, different class duration, and approach to managing students

(3) Reduce scope-the course covers too much material

(4) Change the timeline or scaffold more-in the first term, most Year 7 students are new to their school, and new to their school laptop, network, and environment. They need more support in these initial stages or the programme could commence in the second term

(5) More teachers and more time-some teachers might benefit by being supported for more than two iterations of the course, and some schools will benefit from more teachers taking the CS in Schools programme

(6) Teacher workshop-run a teacher workshop before the programme starts

(7) More tool instruction in the workshop-spend more time on the course materials and the tools in the workshop, in addition to situating volunteers on classroom practices

\section{NEXT STEPS}

We made several changes to the programme for 2020. In terms of course materials, we made two significant changes: first, we reduced the content to eight weeks, slowed the pace of the eight lessons, and added a library of optional supplementary lessons; second, we created a third open-ended exercise at the end of each lesson, which allows advanced students to explore a concept more deeply.

We added a teacher workshop that is focused on introducing coding, setting context about how our course meets the curriculum requirements, and allows time for volunteers and teachers to meet and form an effective team. We also added more tools, course material, and programming environment training for volunteers.

For the 2020 school year, which began in February, we have substantially increased the size of the programme. Around 60 teachers are participating, and around 50 are participating in the way we have described in this paper; approximately 10 teachers are more experienced, and are receiving mentoring from volunteers rather than support in the classroom. We have around 40 volunteers, and some volunteers work with more than one teacher. There are 27 schools in the programme, which translates to more than 6,000 students in the programme for 2020, of which more than half are again non-male. We are also offering a new Year 8 pilot to returning teachers that builds on the introductory Year 7 programme.

We are studying the 2020 offerings both quantitively and qualitatively.

\section{CONCLUSION}

Australian schools are required to teach students to code, yet most schools are not doing so because of a shortage of qualified teachers and the lack of dedicated courses devoted to digital technology. We believe the only way to change this in the short- to mediumterm is to equip existing teachers with the skills to teach coding, and thereby enable schools to teach digital technology to all of their students. Without making urgent and substantive changes, it is unlikely that there will be a step function change in the number students choosing IT as a career.

We have designed, built, and tested a course for entry-level secondary school students that teaches them the fundamentals of coding in Python. We give this course away for free, and help teachers who want professional development support to teach our course. We support teachers by pairing them with a volunteer computing professional who brings content expertise and real-world experience to the classroom. We tested this with ten teachers, eight schools, twelve volunteers, and over 1,100 students in 2019.

We commissioned a qualitative survey of teachers that showed our programme was effective. Teachers universally report an increase in their competence and confidence in teaching coding. We also learnt there was room for improvement, and key changes we have made for 2020 include reducing the complexity and amount of content, running a teacher workshop before the programme starts, and adding more teachers to the programme from each school that we work with.

Eight of the ten teachers in the 2019 programme have returned for a 2020 programme that develops more advanced skills, and seven of the eight schools are continuing to work with us. We have added approximately 20 schools, 50 teachers, and 30 volunteers, largely through recommendations from schools and teachers to other schools and teachers. We believe our programme is successful, and look forward to working with over 6,000 students in 2020. We plan to report quantatively and qualitatively on our work in 2020. Most importantly, we look forward to dramatically changing Australian educational outcomes in digital technology over the next two to three years.

\section{ACKNOWLEDGMENTS}

Toan Huynh is the primary author of the Year 7 materials, and we are deeply grateful for his ongoing contribution. We thank Nicky Carr and Grant Cooper from RMIT University for their help in surveying participants in the programme. We also thank Leigh Jasper, Martin Hosking, and Adam Lewis for their generous philanthropic funding of our work. 


\section{REFERENCES}

[1] Rodger W. Bybee, Joseph A Taylor, April Gardner, Pamela Van Scotter, J. Carlson Powell, Anne Westbrook, and Nancy Landes. 2006. The BSCS 5E instructional model: Origins and effectiveness. Colorado Springs, Co: BSCS 5 (2006), 88-98.

[2] Design and Technology Teachers' Association of Australia. 2019 Technologies Teacher Shortage Survey: National Overview 2019 https://www.dattaaustralia.com/technologiesteachershortage.

[3] Laura M Desimone, Andrew C Porter, Michael S Garet, Kwang Suk Yoon, and Beatrice F Birman. 2002. Effects of professional development on teachers' instruction: Results from a three-year longitudinal study. Educational evaluation and policy analysis 24, 2 (2002), 81-112.

[4] Deloitte Access Economics. 2019. ACS Australia's Digital Pulse 2019 booming today, but how can we sustain digital workforce growth? https://www2.deloitte.com/au/en/pages/economics/articles/australias-digitalpulse.html.

[5] Dan Garcia, Brian Harvey, and Tiffany Barnes. 2015. The beauty and joy of computing. ACM Inroads 6, 4 (2015), 71-79.

[6] Joanna Goode. 2007. If You Build Teachers, Will Students Come? The Role of Teachers in Broadening Computer Science Learning for Urban Youth. Fournal of Educational Computing Research 36, 1 (2007), 65-88.

[7] Nathaniel Granor, Leigh Ann DeLyser, and Kevin Wang. 2016. TEALS: Teacher professional development using industry volunteers. In Proceedings of the 47th
ACM Technical Symposium on Computing Science Education. ACM, 60-65.

[8] Thomas R Guskey and Michael Huberman. 1995. Professional development in education: New paradigms and practices. ERIC.

[9] Mark Guzdial and Elliot Soloway. 2002. Teaching the Nintendo generation to program. Commun. ACM 45 (04 2002), 17-21. https://doi.org/10.1145/505248.505261

[10] V. Darleen Opfer and David Pedder. 2011. The lost promise of teacher professional development in England. European fournal of Teacher Education 34, 1 (2011), 3-24.

[11] Anthony Papini, Leigh Ann DeLyser, Nathaniel Granor, and Kevin Wang. 2017. Preparing and Supporting Industry Professionals as Volunteer High School Computer Science Co-instructors. In Proceedings of the 2017 ACM SIGCSE Technical Symposium on Computer Science Education. ACM, 441-446.

[12] Alexander Repenning. 2018. Scale or Fail. Commun. ACM 61, 5 (April 2018), 40-42. https://doi.org/10.1145/3199603

[13] David C. Webb, Alexander Repenning, and Kyu Han Koh. 2012. Toward an Emergent Theory of Broadening Participation in Computer Science Education. In Proceedings of the 43rd ACM Technical Symposium on Computer Science Education (SIGCSE '12). Association for Computing Machinery, New York, NY, USA, 173-178. https://doi.org/10.1145/2157136.2157191

[14] Paul R. Weldon. 2015. The Teacher Workforce in Australia: Supply, Demand and Data Issues. Australian Council for Educational Research. https://research.acer.edu.au/. 